\title{
Reply to Willi Semmler's and Lucas Bernard's Comments
}

\author{
Bertrand Munier \\ GRID, IAE de Paris /ESTP/Arts-et-Métiers ParisTech and Momagri, 30, Avenue President Wilson, F-94230 \\ Cachan, France, and NYU Polytechnic Institute, New York, USA \\ E-mail: bertrand.munier@wanadoo.fr
}

\section{Introduction}

I feel very thankful to Willi Semmler and Lucas Bernard [5] for their nice and insightful comments. They make several interesting points:

(1) The idiosyncratic adjustment mechanism which emerges from our model [4].

(2) Some points of potential incompleteness and insufficient complexity of our model.

(3) The moderate importance of the volatility of agricultural commodities as compared with nonagricultural ones.

(4) What really Financialization means.

(5) Should the "Walrasian paradigm" be altogether abandoned?

On several of the arguments put forward in the above "Comments ...", I feel in agreement with Semmler and Bernard. But we probably do not share exactly the same point of view on a couple of questions. The quality of their "Comments ..." appears precisely because distinguishing between these two categories of issues can be accomplished without any ambiguity. I take up the 5 points above successively.

\section{The adjustment mechanism involved and the ignorance of the price trend}

The authors of the "Comments ..." point out quite rightly that our adjustment mechanism borrows from different traditions, namely from the cross-dual 'classical' dynamics mechanism to the extent that producers respond to the anticipated price, on one hand, and on the other hand from the "Keynesian dual dynamics" to the extent that inventory changes have no direct impact on prices but only an indirect one through short-term investors, who correct only when there is too strong a discrepancy between the anticipated price and the realized price at the end of the previous campaign, and then react in a way that depends from the importance of the discrepancy [2]. However, they write "there are elements of both mechanisms in [4], but more of the second type". I fully agree. The impact of investors on price formation is way more important than that of farmers in our model as designed in the article, and Semmler and Bernard are right in writing that dual dynamics receives in our model finally more importance than the cross-dual "classical" Walrasian adjustment process. Quite rightly also, they point out that the model borrows from the traditional representative agent on the producer side as well as from the "agent-based" type of modeling on the investor side. The reason for choosing to have a traditional "representative producer" on each market is to be related to the institutional fact that farmers, at least in industrialized and most emerging countries, work closely within a network of cooperative or technical advisory organizations, a fact which has an impact on expectation formation. Admittedly, farmers are said to be fierce individualists, and it might sometimes be difficult to decide what factor overweighs the other. The discussion could be lengthy. The important point, in my view, is that Semmler and Bernard consider as being "a good point" the informational externality argument. Traders in these markets acknowledge also that many of either type of the short term investors have been newcomers on the market during the last decade and have changed the psychology of these markets. I could have made the point of these externalities more explicit and entered into some more complications, but the basic point is sufficient here. 


\section{On the potential incompleteness and insufficient complexity of the model}

I agree with Semmler and Bernard on their remark that the model presented is somehow incomplete on the dynamics of inventories. What is the fate of inventories according to the model? We learn that inventories increase in situations of oversupply (which is likely, though not certain) and conversely (same remark). This is because I only need the changes in inventory level to model investor behavior. Yet, in a next version, I would have to tell a more complete story, relating more explicitly inventories to the movements of prices. I don't think it will change much the results, but I admit it should be done.

In connection to this issue, the reader might feel like I forgot about the role of the price trend in expectation formation. But I would have to express some disagreement with Semmler and Bernard on this point. With the small team mentioned in the text, we have investigated that issue with a number of farmers. There is among them a constant reference to the past trend as to something observed, but we have noticed that the observation is very quickly disconnected from expectation formation. This is why we have chosen to build a model with memory - a feature which doesn't particularly help if one looks for a large volatility as an output of the model - but a relatively short memory. The recent trend (three years back) is, indeed, incorporated in the model through the $\theta(\cdot)$ function, which even captures the speed of that trend. But a longer trend is not taken into account, because this wouldn't match agents' observable behavior.

Semmler and Bernard fear that our demand schedules might tend to infinity, in other words that they would not have any intersection point or "upper bound" with the price axis. This is not to be feared, because we use adjustable affine functions approximating the demand schedule, the value of elasticity being taken in each agricultural sector from recent observations (GTAP data). So, the intersection point might go up quite a bit, but clearly never to infinity, for observable data.

\section{The volatility of agricultural vs. nonagricultural commodities}

Price volatility of agricultural commodities has always been important. It is one of the oldest stories in economics, reported in ancient times and well docu- mented by historians like Leroy-Ladurie [3] and several others. The interesting point is that the clear correlation with yearly climatic changes has vanished since the late 1800 s. Yet, the volatility has continued in its own way and the merit, if any, of the model I have suggested is to provide a plausible explanation of it. Yet, the volatility has been increasing in the last decade, and the explanation had to be also consistent with that observation (see the next discussion point on this issue and the reference to [6]). Semmler and Bernard [5] remark however that the volatility of nonagricultural raw products has been higher than the one of agricultural commodities and claim that we should not overemphasize the phenomenon with respect to the agricultural markets. My view here is slightly different. I certainly have no quarrel with their Fig. 1 and their Table 1 (see however part of the data from [6]). But what about the social impact of the volatility of agricultural products? What about the strategic impact? I deem agricultural volatility as being much more significant than the other raw products price movements, not only because citizens of the world have to eat every day - while they can dispense with some oil for some period of time - but also because of the stronger irreversibility of their current decisions under uncertainty. You can easily stop producing oil at a high pace - an argument that Jeff Frankel makes when discussing inventory changes in oil - you cannot stop wheat from growing once sown. And conversely, if you have sowed at the wrong period, it might be very difficult to "push" the growth of your beans, while you can "push up" production of your oil. There is in what I call the "macro-structure" of the agricultural markets something specific, substantially different from the other commodities markets, not to speak from the markets of manufactured goods.

\section{On the nature of the financialization process}

In a very interesting development, Semmler and Bernard argue [5] that "Financialization" should not be defined in the somehow narrow way I have done in [4]. It not only consists in investing in derivatives, index options or other "paper" business based on commodities, but should also refer, they argue, to the financing of the production of these commodities on negotiation OTC markets. I agree that they are quite convincing on this point, with obvious reference to the subprimes disaster and a further reference to the recent downturn of sovereign debts ratings. Yet, recent empirical studies like Tang's and Xiong's paper [6] tend to show 
that the most important aspect in the case of agricultural commodities is presumably the investment in options or other derivatives on commodities. They write: “... In four different nonenergy sectors, which include grains, softs, livestock, and metals, we find that, in recent years, their prices have become not only increasingly exposed to shocks to the world equity index and US exchange rate, but also to oil shocks. More interestingly, by comparing the differences in the changes in these exposures between commodities in the two most popular commodity indices, the GSCI (Goldman Sachs Commodity Index) and DJ-AIG (Dow Jones AIG Commodity Index) indices, and those off the indices, we find that the changes are consistently stronger for indexed commodities in each of the four nonenergy sectors. This difference-in-difference result suggests that the increasing exposures of commodity prices to the market-wide shocks and oil shocks were associated with the increasing presence of index investors (our underlining), whose investments are concentrated in commodities in the indices" (p. 3, see also their Figs 1 and 2). The last correlation increases consistently for each product, according to Tang's and Xiong's data, since a time ranging between 2002 and 2004, depending on the commodity (their Fig. 4). Yet, I understand that, in the general case, Financialization should be defined in the more general sense.

\section{On the status of the Walrasian paradigm}

Finally, Semmler and Bernard [5] deem that "Most significant is (in [4]) the departure from the Walrasian paradigm" (their conclusion, line 2). Their comments in their first paragraph lead to think that they are rejecting the Walrasian "tâtonnement" as an appropriate description of what happens in markets. Does this mean that we have to send to the waste basket $90 \%$ of the economics literature? Though they do not write anything close to that in their above "Comments ...", one might think that their way of looking at economics would condemn using any kind of Walrasian modeling. I hold a sensibly different view. I think that the Walrasian "tâtonnement" is of course a pure fiction, as I made clear in my text, quoting incidentally Walras himself [7], and cannot describe in detail any of the price formation mechanisms at work. But I think that a Walrasian model can serve as a useful approximation of the adjustment to formed (realized) prices. I even think that it may serve as an instrumental approximation of price formation on markets with weak volatility and limited or inexistent financialization (both rein- force each other and obviously belong to the same vicious circle). In such cases, expectations of producers differ but only slightly from the previously prevailing price, speculators are restricted to a costly spot market for potentially insignificant profits, i.e., play virtually no role whatsoever. There is little chance on such markets that the future-flows securitization process could ever take place. Under such conditions, the Walrasian story can be seen a simplification, saving us a lot of pain. This is why, once the prices formed on agricultural markets, we let them enter a more standard computable general equilibrium model (CGEM) as constraints, we let the CGEM run once, producing revenues which enter in turn the agricultural price formation module (also called the "risk module"), which completes the general adjustment.

If there were no financialized market, the Walrasian adjustment simplification could probably serve on almost every market. The major problem I see with the Walrasian model is that hurried, or careless, or "mathematics blinded" economists are too often led to believe that the Walrasian model has such a general power that it is the market model we should trust under every circumstance [1]. These economists are misled when it comes to financialized (in a sense encompassing Semmler's and Barnard's definition as well as mine) markets, to the financial market itself and presumably a few others. The Subprime story should let us learn our lesson.

\section{References}

[1] R.E. Just, Addressing the changing nature of uncertainty in agriculture, American Journal of Agricultural Economics 83 (2001), 1131-1153.

[2] A. Kirman, Epidemics of opinion and speculative bubbles in financial markets, in: Money and Financial Markets, M. Taylor, ed., Blackwell, Oxford, 1991, pp. 354-368.

[3] E. Leroy-Ladurie, Histoire humaine et comparée du climat, Fayard, Paris, Vols I, 2004; II, 2006 and III, 2009.

[4] B. Munier, Boundedly rational exuberance on agricultural commodities markets, Risk and Decision Analysis 2(1) (2010/2011), 33-50 (this issue)

[5] W. Semmler and L. Bernard, "Boundedly rational exuberance in commodity markets" - Some comments on Bertrand Munier, Risk and Decision Analysis 2(1) (2010/2011), 51-58 (this issue).

[6] K. Tang and W. Xiong, Index investing and the financialization of commodities, Working paper, NBER and Princeton University, 2009.

[7] L. Walras, Eléments d'Economie Politique Pure, Pichon et Durand-Auzias, Paris, 1926 (Original edn, 1874). We refer here to: Dockès et al., CEuvres Complètes d'Auguste et Léon Walras, Band VIII, Economica, Paris, 1988. 